\title{
EMPLOYEE BENEFITS IN SMALL MEDIUM ENTERPRISES (SMES): PRACTICE AND CHALLENGES
}

\author{
Tan Sek-Choo ${ }^{1}$ \\ HabibahTolos ${ }^{2}$ \\ Norlida Abdul Manab ${ }^{3}$
}

\begin{abstract}
$\underline{\text { Abstract }}$
This paper examines the emerging issues in the practice of Employee Benefits (EB) in SMEs. An insight of the types of employee benefits (EB) rationally offered in business is brought forward with its importance. Costs, minimum wage policy, non-monetary benefits, tax implications and cafeteria plan flexibility have been identified as issues and challenges for EB practices in SMEs. This paper contributes knowledge on the contemporary state of EB to the SMEs.
\end{abstract}

Keywords: Employee benefits, SMEs

\section{INTRODUCTION}

Many small-business owners mistakenly believe they cannot afford to offer benefits. Important components of running a successful business is keeping employees happy and providing them with enough incentive to maximize their productivity.Research has proven that a happier workforce is a more productive and people will stay longer in their jobs (McMath, 2011). The 8th Annual Study of Employee Benefits Trends by MetLife in 2009 found that employees perceive their workplace benefits as to help them establish financial security. Although, the primarily motivation was to perform their job functions, employeesare also motivated by the need for financial stability. The financial products of employee benefits include health and other insurance products and retirement savings. These benefits, according to the survey, are referred as "foundation of their personal safety net".Employee benefits (EB) play an important part in what is known as "people strategies".Improving the overall well-being of employees will help them establish better work/life integration. Consequently, the performance of the companies will also be improved.

The term employee benefits (EB) refers to compensation other than an hourly wage or salary (Martocchio, 2014). It represents an important componentof total compensation packages offered by employers. The implications of employee benefit decisions are among the most relevant for remaining competitive in the labor market. In spite of the prominence of the of EB issues to organizations, there is surprising general absence of attention given to EB when reviewing the human resource management (HRM) literature (Dulebohn et al., 2009). Indeed, Deadrick and Gibson (2007) in their analysis of gaps between HRM academic research and

\footnotetext{
${ }^{1}$ Lecturer at Department of Banking and Risk Management, School of Economic, Finance and Banking (SEFB), Universiti Utara Malaysia..Email: tan@uum.edu.my

${ }^{2}$ Senior Lecturer at Department of Banking and Risk Management, School of Economic, Finance and Banking (SEFB), Universiti Utara Malaysia.Email:habibaht@uum.edu.my

${ }^{3}$ Senior Lecturer at Department of Banking and Risk Management, School of Economic, Finance and Banking (SEFB), Universiti Utara Malaysia. Email: norlida@uum.edu.my
} 
practitioner interests found that the largest gap was in the areas of compensation and benefits. Thus, it is hope this paper may possiblyaddress this gap by identifying core topics in the EB literature and discussed the emerging issues.

The basis for understanding the employment relationship lies in the concept of social exchange, which is the most basic concept explaining social behavior. According to Homans(1961) all social behavior can be seen as "an exchange of an activity (work effort)", tangible (visible performance), or intangible (motivation and commitment), and more or less rewarding or costly (pay and benefits), between atleast two persons (employee and employer). Thus social exchange in the employer-employee relationship is one in which the employer offers inducements (such as wages and EB) in return for employee contributions such as performance and commitment (March \& Simon, 1993).

At the employer side, the EB notonly offer cost advantages and tax incentives, but act as a recruitment tool for attracting and retaining desired employees. Whilst at the employee side, EB provides economic and income security, and personal and family welfare. People choose to work for exchange of remuneration. While salary act as a basic remuneration, EB act as a remuneration for the welfare of employees as fulfill such needs as health care, dependent care, retirement planning, vacations, and education. As such, in exchange, they elicit increased motivation and commitment from employees toward the company goals (Martocchio, 2014). Thus, apart from meeting the government regulations, EB are offered to lure the best applicants to an organization and also to retain the existing workforce. Some industries are highly competitive and therefore must compete for the most qualified potential employees.

The next section describes the types of EB and its importance. The third section discusses the issues and challenges surrounding EB practices in SMEs. Finally, the last section concludes the discussions.

\section{TYPES OF EMPLOYEE BENEFITS}

The EB represent virtually any form of compensation other than direct wages, and it could be paid for wholly or partially by employer; and can be provided by a third party such as the government, insurance company or health maintenance organization (Employee Benefit Research Institute, 1987). Arguably, it is a challenge for SMEs to provide comprehensive EB programs because any additional programs are a cost to the company.

The EB in the context of total compensation systems in companies can be depicted in Figure 1 below. It represents both monetary and non-monetary rewards. Non-monetary compensation includes protection program such a medical insurance, paid time off such as vacations and services such as day care assistance. Benefits vary and serve different social and economic needs. Note that companies may offer additional benefits on a discretionary basis. These benefits are also different between companies. It is common for companies to look at EB in the form of mandatory (compulsory) benefits versus the discretionary (fringe) benefits. According to Martocchio (2014), discretionary benefits fulfilled three main roles namely protection programs, paid time off, accommodation and enhancements.

Legally required benefits (mandatory benefits) are mandated by laws. The EB in Malaysia is bound laws such as The Employment Act 1955, which covers manual workers and non- 
manual workers, provide minimum benefits and rights of employees and others. Similarly the Employment (amendment) Act 2000, the Employees Social Security Act 1969, Employees Provident Fund Act 1991 and Pensions Act 1980 also play role in the Malaysian EB.

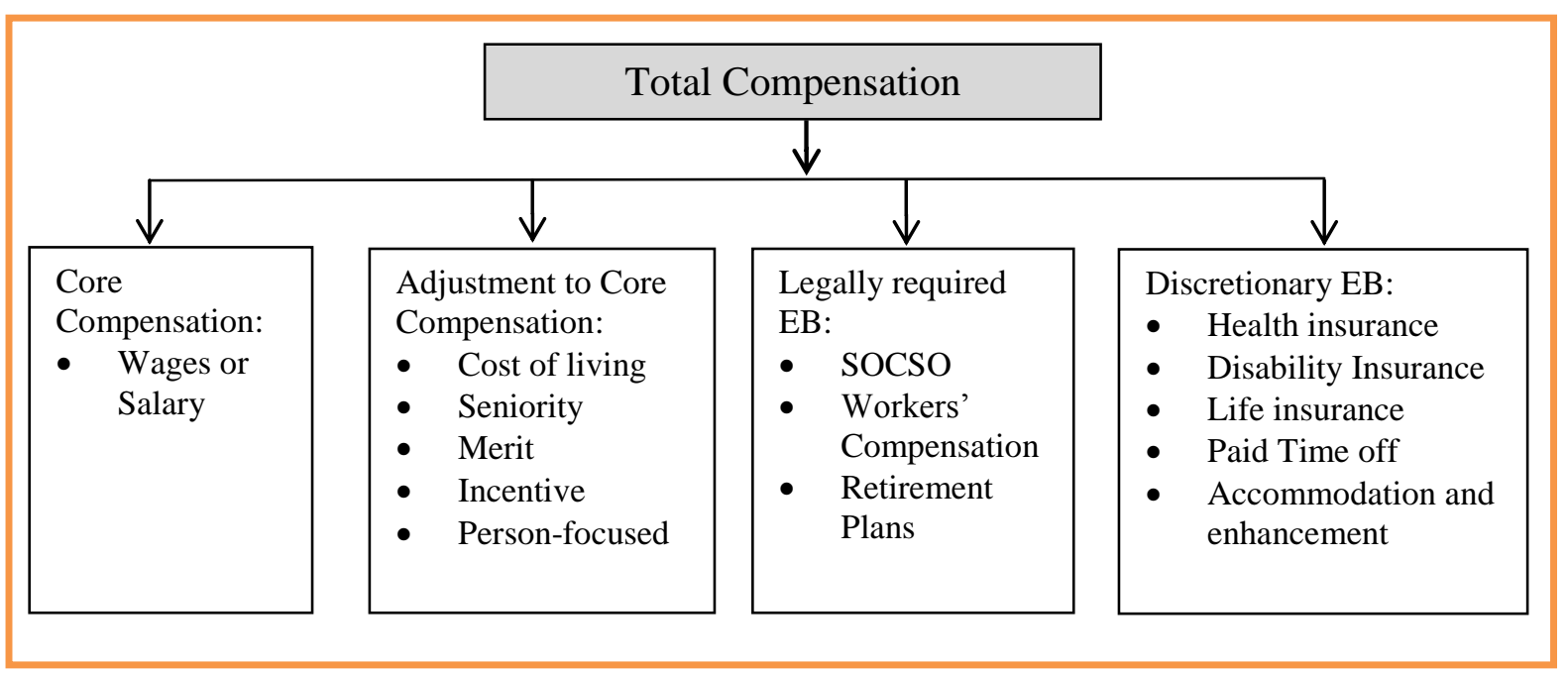

Figure 1: Employee Benefits in the Total compensation Scheme in Malaysia

\section{THE IMPORTANCE OF EMPLOYEE BENEFITS}

From employees perspective, EB can serve to provide for employees various needs such as to provide certain level of living standard based on employee's relative position and job responsibilities; to incentivize employees performance; to provide protection against loss of income due to critical illnesses, disability or premature death; to provide protection against medical expenses; to provide retirement income; to offer opportunities for capital accumulation; sound retirement, financial and tax planning programs and services to assist employee planning for a secure retirement. On the other hand, from employer perspective, EB can serve to motivate, attract and retain talents; as incentive for above-average performance; enable companies to fulfill its social obligations to the employees (Hallman \& Rosenbloom, 1986).

An attractive employee benefits programme will affect on staff recruitment and retention, and consequently a risk of turnover rate can be reduced (Zahorsky, 2014).Successful organizations realized that employee retention was an important to sustain their leadership and growth in the marketplace (Mello, 2006). According to Chui et al. (2001) EB have been used to attract, retain, and motivate employees and achieve organizational goals. The EB policy might be used specifically to retain top workers as well as win out over competitors who have high executive turnover rates. Ahmad et al. (2013) study on the relationship between types of benefit and employees' retention confirmed that there was a positive relationship between leave, loan and retirement plan with employees' retention. Leave benefit was the dominant factor in retaining the employees among the public university employees. The implication of this research supports that the combination of non-monetary and monetary types of benefit do affect the employees' retention.

The most common employee benefits offered by small business were paid vacations $(75 \%)$, employee Health insurance plan (61\%), paid sick leave (59\%), disability insurance (41\%), 
education reimbursement for job (39\%), pension plan (30\%), life insurance (29\%) and dental insurance (24\%) (Zahorsky, 2014). Therefore, a strong benefits package can help provide the financial stability of the employees and establish better work/life integration. Ju et al. (2008) studied on employees in food manufacturing industry in Malaysia and found that mandatory benefits and fringe benefits were positively influenced organizational commitment. This indicates that when employee received more fringe benefits, their organizational commitment tend to be higher. Therefore the employers should not only provide mandatory benefits as required by law, but also provide discretionary benefits in order to strengthen the employees' organizational commitment, motivation, productivity and job performance.

In contrast, prior study by Dasahi et al. (2005) revealed that most of the benefits offered in SMEs are those that comply with the statutory requirement under the Malaysian Employment Act 1955. Those benefits are paid-time off, annual bonus, employee provident fund, medical care and staff training. On the other hand, only a few companies offered other benefits that do not fall under the mandated categories. This is because most of the SMEs are lacking of experts in the EB areaalthough they perceived EB program as an important element in motivating the staff as a whole. In addition, it was found that most SMEs employers have positive perception in offering EB in their companies. This study also revealed that employers agree that employee benefits program is an important element in ensuring their employee's job-satisfaction. In turn, employees are satisfied with the employee benefits program offered by the companies concerned.

\section{ISSUES AND CHALLENGES OF EMPLOYEE BENEFITS}

\section{Cost}

The first challenge in providing $\mathrm{EB}$ is an issue of additional costs. SMEs biggest developmental challenges normally concerned with limited size especially salient with regard to innovation and finance (Herrmann-Pillath, Li Kai, \& Pan Jiancheng, 2002). Based on SME Corporation Malaysia (2013) report, labour cost is the second largest cost after raw material and other input costs for SMEs. EB is seen as equal to employer burden where benefit packages usually comprise of one third and one quarter of total personnel compensation, the costs of EB have escalated at an annual rate of $6.2 \%$, easily outpacing the inflation rate (Ghio, 2002). Wal-Mart USA, for instance has experienced rising EB cost by average of $15 \%$ per annum since 2002. This is due to increase in health care costs which prompting the company to implement cost cutting measures by restructuring the EB. The proposed cut on EB costs could save company more than $\$ 1$ billion per year despite anger from employees (The New York Times, 2005).

Employers' have various options to deal with the rising EB costs issues. It is proven by Frostin,Helman\& Greenwald (2003) that employers tend to adapt the EB structure of the companies in adjusting to the increased costs. One way is to pass the bulk of the costs to employees by increasing share of premiums payable for health care or to reduce benefits offered to workers. This can be done by decreasing the quantity and quality of benefits. The second option is by reducing the number of workers who are offered such benefits. The third option is to employ temporary workers. However, there is caveat in employing temporary workers as in the case of Microsoft's freelancers Vizcaino v. Microsoft, which lead to nearly $\$ 100$ million settlement (Ghio, 2002). Kronick, Olsen \& Gilmer (2008) measure the responsiveness of SMEs offering subsidized insurance coverage in two premium choices. 
They found that the premium choice of $\$ 20$ per month an estimated $40 \%$ of taken up rate. On contrary, at $\$ 100$ per month the take-up rate was only $13 \%$. However, SMEs not offering insurance to employees are not very responsive to large reductions in price of coverage. This indicates that programmes to subsidize insurance for SMEs and their employees failed to reduce the number of uninsured persons. Frostinet. al. (2003) also found that 3\% of SMEs would drop coverage if the cost of health benefits were to increase an additional $5 \%$.

\section{Minimum Wage Policy (MWP)}

Second issue to consider is the trade-offs in EB offering and impact of minimum wage policy. A study by AON Hewitt (2011) concluded that compensation and benefits to be most affected by minimum wage policy. Further, employers need to adjust the salary and benefits of the low-wage employees in order to be in compliance with the policy. Without the enactment of MWP, employers should be more generous in offering the EB package.In Thailand, there is an argument that SMEs are not able to support the costs of the minimum wage. Consequently, private sector bodies have called on the government to set up a compensation fund for the Thai businesses to alleviate the impact of the wage hike. Despite the government rejection, a number support measures had been implemented. For example reducing employers' contribution to the Social Security Fund from 5\% to 4\%, cutting fees for hotels in the SMEs category by $50 \%$, reducing withholding tax for SMEs from $3 \%$ to $2 \%$ and reducing the corporate income tax from 30\% to 20\% in 2013 (Alexander, Salze-Lozach, \& Winijkulchai, 2013). In Malaysia, the minimum wage policy would impact 1.8 million workers mostly migrant workers. The cost could go up as much as $10 \%$, while the labour cost of foreign workers in SMEs is estimated to increase 40\% to 60\% (Yong, 2014).

\section{Non-monetary benefits}

Thirdly, there is an emerging trend in non-monetary benefits partly because of demographic changes in the labour force especially the emergence of dual-income family. This led to the creation of various non-monetary EB to cater for employees and their families (Marshall, 2003). Besides, EB also has evolved to entice and retain skilled workers with non-monetary compensations. Example of non-monetary EB areworking schedule flexibility, on-site child care, maternity/paternity leave, awards and recognitions, counselling, wellness or fitness programmes, workplace financial education, and other related employee assistance programmes.

The Integrated Benefits Institute reported that due to poor health, the U.S. economy lost $\$ 576$ billion a year.They reported a 39\% ( $\$ 227$ billion) "lost productivity" caused by illness related absenteeism. This is also known as "presenteeism," when employees report to work but unable to perform at their best due to illnesses(Japsen, 2012). Hence, companies are now aware that they can help employees to adopt healthier lifestyles. The adoption of workplace health promotion at SMEs was motivated by three objectives, which are to lower health care costs, to address human relations and to improve productivity (Witt, Olsen, \& Ablah, 2013). A study from four different countries supported the premise that health determines employment, which referred to as healthy-worker effect. Conversely, relationship between health and employment also exists, with employment improving health (Hartman, 2008).

The concern of financial education to employees is one of the highly emphasized forms of non-monetary benefits. The workplace financial educational programme provides employees with information about financial decisions and retirement planning. As such it is proven that financial education stimulates saving, both in general and retirement savings(Bernheim 
$\&$ Garrett, 2003). Nowadays, there are greater responsibilities for employees to set up their retirement fund by themselves. The complexities of the business environment and the fact the life-long employment and job security is no longer prevalent, there is trends towards selfreliance where employees are encourage taking responsibility for their future retirement (Garacci \& Kleiner, 2003). For example, Malaysia has introduced Private Retirement Scheme (PRS) in 2012 to supplement the current Employee Provident Fund (EPF). Thus employees need to acquire adequate financial skills to make such decisions.

Special needs care for employees are also a latest trend in EB offered as recorded by literatures. This might due to the increase of percentage of employees with special children. For example, in the United States there are about $13 \%$ to $15 \%$ of children who need special health care. The demand of their caregiving can affect the parents' health and workplace performance (Perrin, et al., 2007), this lead to another concern on employees' absenteeism. Family owned SMEs especially were concerned about the financial implications on their organizations if workers were absent from work (Holt \& Powell, 2014). Hence, provisions for back-up and preventive services in the workplace proven to be effective deterrent to absenteeism and turnover. A study by LoJacono (2001) found that $\$ 1$ investment in the cost of mildly ill/back-up child care return $\$ 2$ to $\$ 3$ to the bottom line. While family with aging parents may need support in terms of elder care assistance. This suggested that trends of discretionary EB offered shall cover the needs of family in spite of employee solely.

\section{Tax implications}

A study in the United States found that of SMEs who did not offer health insurance benefits, $57 \%$ of them were unaware that they can get $100 \%$ tax deductions of the health insurance premiums (Fronstin, Helman, \& Greenwald, 2003). Different countries have different tax treatment on the EB expenses. For example, the Malaysian government provides personal income tax relief for private retirement schemes (PRS) contributors as an effort to encourage voluntary retirement savings. However the tax relief claimable is capped at RM3,000. Employers are provided tax deductions on contributions to PRS made on behalf of their employees above the statutory rate and up to 19\% of employees' remuneration. Tax exemption is also provided on income received by the PRS funds. SMEs may utilize PRS as a tool to retain employees for a certain desired period using vested interest mechanism.

In Malaysia, the Goods and Services Tax (GST) impact on EB is particularly interesting as it may change the way in which employees are rewarded by their employer come $1^{\text {st }}$ April 2015. This is due to the fact that different type of supply will lead to different tax treatment depending on the GST rules.Companies need to understand how the GST rules and regulations impacting to $\mathrm{EB}$ offerings so that $\mathrm{EB}$ can be designed in the most tax efficient manner.

One of the most underused employee benefits available for SMEs in the United States is outlined in section 125 of the U.S. tax code, known as the "cafeteria" plan (Bryson, 2005). A cafeteria plan is EB plans that provide flexibility of choicefor employee to create benefits plan that best meets their needs and those of their family. The tax free EB plan allows employees to withhold a portion of their pre-tax salary to cover certain medical or child-care expenses. Thus reduces employees' taxable income. Consequently, increases the percentage of take-home pay. On the other hand, since pre-tax benefits are not subjected to federal social security withholding taxes, employers benefitted by not having to pay workers' compensation premiums. 


\section{Cafeteria plan flexibility}

Many employers offer a "one size fits all" benefits plan, and as a result, do not provide the benefits their employees really need. Cafeteria plan can empower employees by allowing them to design their own benefit packages. Employers' understanding is crucial in determining whether cafeteria plan is right for their organization. In United Kingdom, Research by HR consultancy Towers Watson revealed only $27 \%$ of companies offered a flexible scheme, up just $8 \%$ since 2007 , and that $32 \%$ of employers said take-up rate of such schemes was lower than expected (Hemsley, 2013). The key to running a successful flexible benefits programme are simplicity and benefit communications. Simplicity means EB features and advantages must be stated and designed in a manner that is easily comprehend by employees. While benefit communications should enable employees to see how the benefits can be designedoptimally to tailor to their objectives. Most importantly,employers need to ensure employees act upon in choosing the best EB benefits based on their own objectives. Active employee engagement is at the best to be deployed with the help from EB experts. However, as cited earlier the challenge facing SMEs is lacking of EB expertise. High degree of employee engagement would impact employees positively via improved performance, increased retention, enhanced productivity, increase loyalty and enhanced employer reputation (Vogel, 2006).

\section{CONCLUSION}

EB is part and parcel of employment practices. The discussion has provided insights into the state of the practice and challenges of EB in SMEs. Employers offer EB beyond salaries and wages to retain their staff and "make them happy". Hence, the EB design and package will keep evolved with the change in regulations, technology, work force demographic and lifestyles of employees. Employers would rather spend to retain existing employees rather than keep recruiting new employees due to high costs and time consumed.

The dynamics of the SMEs and workforce have given rise to the awareness of the role of EB as a conduit for employers to be seen as socially cared, while employees focus on their job roles. It is a win-win contract of social exchange as both employers and employees gain their intended objectives.

The way employees were compensated decades ago are different from today as EB continues to evolve. SMEs now are also able to stand tall with their multi-national corporations (MNCs) counterparts in offering competitive EB to their employees. However, providing higher level of EB comes with a price. The constant pressure on costs was worsening by the enforcement of minimum wage policy in certain countries recently such as Thailand and Malaysia. This has distorted the costs structure of SMEs which may force them to reassess the EB offered. Besides the mandatory benefits, there is increasing trends towards providing non-monetary benefits and cafeteria flexibility plan. The tax implications of EB could not be ignored by employers and employees as it would impact the design or choices of benefits.

In Malaysia, EB is a subject which is not widely researched by academics as there is scarcity in literatures pertaining to EB, especially EB in SMEs. Therefore, it is a challenge for the academics to undertake such research tasks to understand the various aspects of EB practices and critical issues in helping SMEs with their EB policies, as cited earlier that SMEs are lacking of experts in this area. In addition, it may help the law makers improvise the system being practiced currently. 


\section{REFERENCES}

Ahmad, R., Toh, P.,Y, E., (2013) Relationship between Types of Benefit (leave, loan and retirement plan) and Employees' Retention.International Journal of Education and Research Vol. 1 No. 8.

Alexander, S., Salze-Lozach, V., \& Winijkulchai, A. (2013). Thailand Adopts Nationwide Minimum Wage Policy Amid Controversy.www.asiafoundation.org.

Bernheim, B., \& Garrett, D. (2003). The effects of financial education in the worklplace: evidence from a survey of households. Journal of Public Economics, 1487-1519.

Bryson, T. D. (2005, september 14). Entrepreneur. Retrieved July 22, 2014, from Entrepreneur: http://www.entrepreneur.com/article/79978

Chui, R. K., Luk, V. M. N. \& Tang, T. L. P. (2001). Hong Kong and China: the cash mentality revisited, Compensation and Benefits Review,33 (3), 66-77.

Colling, J. (2013). Positioning wellness solutions within employee benefir strategies. Strategic HR Review.

Dasahi, N.,Manab, N.,\&Bakar, A., B., (2005)Employee Benefits Management Practices: A study on SME. Proceeding -The Northern Region, Seminar KebangsaanSosioekonomi\& IT, Perlis.

Deadrick, D. L. \& Gibson, P.A (2007), Anexamination of the research-practice gap in HR: Comparing topics of interest to HR academics and HR professionals. Human Resource Management Review, 17, 131-139.

Dreher, G., Ash, R., \& Bretz, R. (1988). Benefit Coverage and Employee Cost: Critical Factors in Explaining Compensation Satisfaction. Personnel Psychology, 237-254.

Dulebohn, J.H., Molloy, J.C., Pichler, S. M., \& Murray, B. (2009) Employee benefits: Literature review and emerging issues, Human Resource Management Review, 19,86-10.

Employee Benefit Research Institute (1987), Fundamentals of Employee Benefit Programs, Washington D.C., Educational and Research Fund

Employee Benefit Research Institute. (1987). Fundamentals of Employee Benefit Programs. Washington D.C: Education Research Fund.

Fronstin, P., Helman, R., \& Greenwald, M. (2003). Small employers and health benefits: findings from the 2002 small employer health benefits survey. EBRI Issue Brief, 1-21.

Garacci, T., \& Kleiner, B. (2003). New developments concerning employee benefits and pensions. Management Research News, 89-96.

Ghio, R. (2002). Contingent Workers and Employee Benefits: Do You Know Who Your Employees Are? Sage Publications. 
Hallman, V., \& Rosenbloom, J. (1986). Employee Benefit Planning. Englewood Cliffs: Prentice-Hall.

Hartman, E. (2008). A Literature Review on the Relationship between Employment and Health: How this Relationship may influence Managed Long Term Care. Employment and Health.

Hemsley, S. (2013, June 5). HR Magazine. Retrieved July 22, 2014, from HR Magazine: http://www.hrmagazine.co.uk/hr/features/1077403/flexible-benefits-schemes-receivingsurprisingly-low

Herrmann-Pillath, C., Li Kai, \& Pan Jiancheng. (2002). Problems in he development of small and medium-size industrial enterprises in China. Sage Publications.

Holt, M., \& Powell, S. (2014). Health aand well-being in small medium-sized enterprises (SMEs). What public health support do SMEs really need?? Royal Society for Public Health.

Homans, G.C. (1961), Social Behavior: Its Elementary Forms. New York: Harcourt, Brace \& World, Inc.

Hubbard, J., \& Singh, P. (2009). The Evolution of Employee Benefits at the Economical Insurance Group. Compensation \& Benefits Review.

Japsen, B. (2012). U.S Workforce Illness Costs $\$ 576$ B Annually from Sick Days to Workers Compensation. The Forbes.

Ju, S.Y., Kong, L., Hussin, Z.H \&Jusoff, K. (2008), The influence of employee benefits towards organizational commitment, Asian Social Science, 4 (8), 147-150.

Kronick, R., Olsen, L., \& Gilmer, T. (2008). The Response of Small Business to Variation in the Price of Health Insurance. Medical Care Research and Review, 187-206.

LoJacono, S. (2001). Mildly ill / Back-up Child Care: A Growing Trend in Employee Benefits. Compensation \& Benefits Review.

March, J.G. \& Simon, H.A. (1993) Organizations, (2 ${ }^{\text {nd }}$ ed.) Cambridge, MA: Blackwell.

Marshall, K. (2003, May). Benefits of the job. Retrieved July 22, 2014, from Perspectives on Labour and Income The Online Edition: http://www.statcan.gc.ca/pub/75-001-x/00503/6515eng.html

Martocchio, J. J. (2014), Employee Benefits: A Primer for Human Resource Professionals, ( $5^{\text {th }}$ ed.), Boston: McGraw-Hill/Irwin.

McMath, I, (August, 2011) Employee benefits and staff motivation, RetrievedJuly 6, 2014, from http://www.smeweb.com/

Mello, J. A. (2006), Strategic Human Resource Management ( $2^{\text {nd }}$ ed.) Thomson, Mason, OH, 213-320 
Morrell, D. L. (2011). Employee Perceptions and the Motivation of Nonmonetary Incentives. Compensation \& Benefits Review, 318-323.

Norman, J. (1998). Most workers at small firms without pensions. The Orange County Register.

Perrin, J., Fluet, C., Anderson, B., Wells, N., Epstein, S., Allen, D., . . Kuthithau, K. (2007). Benefits for Emloyees with Children with Special Needs: Findings from the Collaborative Employee Benefit Study. Health Affair, 1096-1103.

The MetLife ${ }^{\circledR}$ study(2009)The Value of Employee Benefits, Retrieved July 6 2014, from http://www.guidestoneinsurance.org/AboutUs/Articles/ValueOfEmployeeBenefits.

Vogel, N. (2006). Meeting Special Needs: A Benefit Thaat Adds Value for Both Employees and Employers. Compensation \& Benefits Review.

Witt, L., Olsen , D., \& Ablah, E. (2013). Motivating Factors for Small and Midsized Buinesses to Implement Worksite Health Promotion. Health Promotion Practice, 878-884. 